\title{
REVIEW
}

\section{Retinitis pigmentosa and allied conditions today: a paradigm of translational research}

\author{
Carmen Ayuso*1 and Jose M Millan²
}

\begin{abstract}
Monogenic human retinal dystrophies are a group of disorders characterized by progressive loss of photoreceptor cells leading to visual handicap. Retinitis pigmentosa is a type of retinal dystrophy where degeneration of rod photoreceptors occurs at the early stages. At present, there are no available effective therapies to maintain or improve vision in patients affected with retinitis pigmentosa, but post-genomic studies are allowing the development of potential therapeutic approaches. This review summarizes current knowledge on genes that have been identified to be responsible for retinitis pigmentosa, the involvement of these genes in the different forms of the disorder, the role of the proteins encoded by these genes in retinal function, the utility of genotyping, and current efforts to develop novel therapies.
\end{abstract}

\section{Introduction}

Human retinal dystrophies (RD) are a group of disorders characterized by a primary and progressive loss of photoreceptor cells leading to visual handicap. Monogenic RD are rare diseases. The most common form of the disease, retinitis pigmentosa (RP), is characterized by primary degeneration of rod photoreceptors and has an estimated prevalence of around 1 in 4,000 [1-4], although higher frequencies have been reported in some Asian populations (1 in 930 in South India [5], and approximately 1 in 1,000 in China [6]). RP constitutes 85 to $90 \%$ of RD cases.

The first symptoms of RP are retinal pigment on fundus examination, and night blindness, followed by progressive loss in the peripheral visual field, eventually leading to legal blindness after several decades. The clinical

\footnotetext{
*Correspondence: cayuso@fid.es

'Department of Medical Genetics, IIS-Fundación Jiménez Díaz/CIBERER, Av/Reyes Católicos no. 2; 28040, Madrid, Spain

Full list of author information is available at the end of the article
}

aspects of RP are shown in Table 1. The clinical presentation can be macular, cone or cone-rod dystrophy (CORD), in which the decrease in visual acuity predominates over the visual field loss, or it can be the only symptom. Cone dystrophy is an inherited ocular disorder characterized by the loss of cone cells, which are the photoreceptors responsible for central and color vision. Typically, age of onset is early teens, but it can be very variable, ranging from congenital forms of the disease (Leber's congenital amaurosis (LCA)) to late-onset RD.

RP is usually non-syndromic (70 to $80 \%$ ), but there are also more than 30 syndromic forms, involving multiple organs and pleiotropic effects, the most frequent being Usher syndrome (USH; approximately 15 to $20 \%$ of all RP cases). USH associates RP with sensorineural deafness and sometimes vestibular dysfunction. The second most common syndromic form is Bardet-Biedl syndrome (BBS), which accounts for 20 to $25 \%$ of syndromic forms of RP or approximately $5 \%$ of cases of RP. Patients with BBS typically present with RP, obesity, polydactyly, renal abnormalities and mild mental retardation.

It is worth noting that USH and BBS are genetically as heterogeneous as isolated RP. To date, nine genes have been identified for USH and 14 for BBS. The existence of patients lacking mutations in any of the identified genes indicates that at least one more gene remains unidentified for both syndromes.

Other syndromic forms of RP include associations with hearing loss and obesity (Alström syndrome), dysmorphic face and kidney deficiency (Senior-Locken syndrome), and metabolic disorders [7]. Table 2 shows the most common disorders involving non-syndromic and syndromic RP.

\section{Patterns of inheritance in retinitis pigmentosa}

Both RD and RP show great clinical and genetic heterogeneity, and they can be inherited as autosomal-recessive (ar), autosomal-dominant (ad) or X-linked (xl) traits. Other atypical inheritance patterns, such as mitochondrial, digenic, triallelic and isodysomy, have also been associated with some RP cases [8].

Almost half of RP cases are sporadic, without any history of RD in the family. Diverse patterns of 


\begin{tabular}{|c|c|}
\hline Clinical signs & \\
\hline Visual function & $\begin{array}{l}\text { Impaired night vision (nyctalopia), myopia } \\
\text { (frequently), progressive loss of visual acuity }\end{array}$ \\
\hline Visual field & $\begin{array}{l}\text { Loss of peripheral vision in early stages, progressive } \\
\text { loss of central vision in later stages, ring scotoma, } \\
\text { tunnel vision }\end{array}$ \\
\hline Eye fundus & $\begin{array}{l}\text { Bone spicule deposits in peripheral retina, } \\
\text { attenuation of retinal vessels, waxy pallor of the optic } \\
\text { disc }\end{array}$ \\
\hline Eye movement & Nistagmus \\
\hline Electroretinogram & $\begin{array}{l}\text { Diminution or abolishment of the a-waves and } \\
\text { b-waves }\end{array}$ \\
\hline
\end{tabular}

inheritance have been reported for non-syndromic cases of RP and their families depending on the geographical origin, the sample size of the study and the methods for clinical ascertainment. A reliable estimate for the percentages of each inheritance pattern could be 15 to $25 \%$ for autosomal-dominant RP (adRP), 35 to $50 \%$ for autosomal-recessive RP (arRP), 7 to 15\% for X-linked RP (xlRP), and 25 to $60 \%$ for syndromic RP [9] (Table 3).

However, well-known genetic phenomena that alter Mendelian inheritance have also been observed in RP. Incomplete penetrance [10] and variable expressivity have been reported in many families with RP. The literature offers many examples of variable degrees of severity of RP among members of the same family carrying the same mutation [11]. In xlRP forms, female carriers sometimes present RP symptoms and can be as affected as male carriers. One explanation for this might be lyonization, that is, the random inactivation of one $\mathrm{X}$ chromosome in females to compensate for the double $\mathrm{X}$ gene dose during early developmental stages. The inactivation of the $\mathrm{X}$ chromosome not carrying the mutation in a cell or cell population that will later develop into the retina could lead to an active mutated RP gene in the female carrier.

\section{Genes involved in retinitis pigmentosa}

The overwhelming pool of genetic data that has become available since the identification of the first mutation associated with RP in humans (a proline to histidine change at amino acid position 23 in rhodopsin, reported by Dryja et al. in 1990 [12]) has revealed the genetics of $\mathrm{RD}$ to be extremely complex. Research into the molecular causes of RD has revealed the underlying disease genes for about $50 \%$ of cases, with more than 200 genetic loci described [13]. These genes are responsible not only for $\mathrm{RP}$, but also for many other different clinical entities such as LCA, macular degeneration and CORD. To date, 26 genes have been identified for arRP and 20 for adRP, and two genes on the $\mathrm{X}$ chromosome (xlRP). For a number of
Table 2. Non-syndromic and syndromic retinal dystrophies and inheritance pattern

\begin{tabular}{|c|c|}
\hline Retinal dystrophy & Inheritance \\
\hline \multicolumn{2}{|l|}{ Non-syndromic } \\
\hline Retinitis pigmentosa & $\mathrm{ad}, \mathrm{ar}, \mathrm{xl}$, digenic \\
\hline Cone or cone-rod dystrophy & $a d, a r, x l$ \\
\hline Leber congenital amaurosis & Mainly ar, rarely ad \\
\hline Stargardt disease & Mainly ar, rarely ad \\
\hline Fundus flavimaculatus & ar \\
\hline Congenital stationary night blindness & $a d, a r, x l$ \\
\hline North Carolina macular dystrophy & $\mathrm{ad}$ \\
\hline Sorsby's macular dystrophy & $\mathrm{ad}$ \\
\hline Pattern macular dystrophy & $\mathrm{ad}$ \\
\hline Vitelliform macular dystrophy (Best's disease) & $\begin{array}{l}\text { ad (incomplete } \\
\text { penetrance) }\end{array}$ \\
\hline Choroideremia & $x \mid$ \\
\hline X-linked retinoschisis & $x \mid$ \\
\hline Gyrate atrophy & ar \\
\hline \multicolumn{2}{|l|}{ Syndromic } \\
\hline Usher syndrome & ar \\
\hline Bardet-Biedl syndrome & ar, oligogenic \\
\hline Senior-Locken syndrome & ar \\
\hline Alport syndrome & $\mathrm{xl}$ \\
\hline Älmstron syndrome & ar \\
\hline Joubert Syndrome & ar \\
\hline Nephronophthisis & ar, oligogenic \\
\hline Cockayne syndrome & ar \\
\hline Refsum disease & ar \\
\hline Autosomal dominant cerebellar ataxia type 7 & $\mathrm{ad}$ \\
\hline Norrie disease & $x \mid$ \\
\hline
\end{tabular}

ad: autosomal dominant; ar: autosomal recessive; $\mathrm{xl}$ : X-linked.

these genes, some mutations in the same gene lead to autosomal-dominant forms, while some other mutations lead to autosomal-recessive forms.

Different mutations in several genes lead to syndromic forms such as USH or isolated RP (USH2A gene) or nonsyndromic deafness (MYO7A, CH23, PCDH15, USH1C and $U S H 1 G$ ), and mutations in the same gene can cause different clinical entities, as has been observed for $A B C A 4$, which is implicated in arRP, autosomal-recessive macular dystrophies (arMD) and autosomal-recessive CORD (arCORD). Furthermore, most of the mutations causing RP are exclusive to one or a few individuals or families. Common mutations and hot spots are rare; therefore, there is a need for large and time-consuming mutation screenings to achieve a molecular diagnosis of $\mathrm{RP}$ in patients. In addition, there is no clear genotypephenotype correlation and, in many cases, relatives 
Table 3. Geographical distribution of genetic types

\begin{tabular}{|c|c|c|c|c|c|}
\hline Country and reference & Non-syndromic RP ( $n$ ) & $\operatorname{adRP}(\%)$ & $\operatorname{arRP}(\%)$ & xIRP (\%) & Syndromic RP (\%) \\
\hline Spain [55] & 1,717 & 15 & 34 & 7 & 41 (3 unclassified) \\
\hline France [56] & 153 & 19 & 35 & 4.1 & 41.3 \\
\hline The Netherlands [57] & 575 & 22.4 & 30.1 & 10.4 & 37.1 \\
\hline Switzerland [1] & 153 & 9 & 90 & 1 & - \\
\hline Germany [58] & 250 & 25.2 & 16.4 & 10 & 48.4 \\
\hline UK [59] & 300 & 39 & 15 & 25 & 21 \\
\hline USA [60] & 138 & 22 & 10 & 14 & 37 \\
\hline USA [61] & 489 & 14.1 & 13.7 & 7 & 65.2 \\
\hline Japan [62] & 1,091 & 2.1 & 40.1 & & 43.2 \\
\hline Japan [63] & 434 & 16.9 & 25.2 & 1.6 & 56.3 \\
\hline China [64] & 150 & 13.3 & 67.3 & 2.7 & 16.7 \\
\hline South Africa [65] & 63 & 21 & 15 & 10 & 54 \\
\hline USA [66] & 68 & 6 & 13 & 7 & 74 \\
\hline
\end{tabular}

adRP: autosomal-dominant retinitis pigmentosa; arRP: autosomal-recessive retinitis pigmentosa; RP: retinitis pigmentosa; xIRP: X-linked retinitis pigmentosa.

bearing the same mutation display very different forms of $\mathrm{RP}$ in terms of age of onset and severity.

Many genes and proteins are associated with RD. These proteins are involved in retinal functions, but they can also play other roles such as degradation of proteins in the retinal pigment epithelium, and ionic interchange or trafficking of molecules in the ribbon synapse of photoreceptors. Tables 4, 5, 6 and 7 summarize the genes involved in RD, their chromosomal locations and functions, and the proteins they encode. The major pathways involved in pathogenesis of RP are discussed below.

\section{Phototransduction}

Phototransduction is the process through which photons are converted into electrical signals. It begins with the light-induced isomerization of the ligand of rhodopsin, which is 11-cis retinal, and the activation of rhodopsin. Rhodopsin undergoes a change in conformation upon photoexcitation and activates the $G$ protein transducin. GDP-bound inactive transducin exchanges GDP for GTP, and GTP-bound active transducin increases the activity of cGMP phosphodiesterase. The result is decreased levels of cGMP in the cytoplasm, and this causes the closing of cGMP-gated ion channels and leads to membrane hyperpolarization. The recovery of the phototransduction process is carried out by the phosphorylation of rhodopsin by a receptor-specific kinase, rhodopsin kinase. The phosphorylated photoactivated rhodopsin is bound by arrestin, thereby terminating activity of the receptor in the signal transduction process. Mutations in the gene encoding rhodopsin (RHO) are responsible for adRP, arRP and dominant congenital stationary night blindness. Mutations in the genes for cGMP phosphodiesterase alpha and beta subunits (PDE6A and PDE6B, respectively) are responsible for arRP and dominant congenital stationary night blindness. Mutations in the genes encoding the rod cGMP-gated channel alpha and beta subunits (GUCA1A and GUCA1B, respectively) are responsible for arRP, while arrestin ( $S A G)$ is involved in Oguchi disease. The genes encoding guanylate cyclase activating protein $1 \mathrm{~B}(G U C A 1 B)$ and cone alpha subunit of cGMP phosphodiesterase $(P D E 6 C)$ are responsible for dominant $\mathrm{MD}$ and $\operatorname{arCORD}$, respectively.

\section{Visual cycle}

After isomerization and release from the opsin protein, alltrans retinal is reduced to all-trans retinol, and it travels back to the retinal pigment epithelium to be 'recharged'. It is first esterified by lecithin retinol acyltransferase and then converted to 11-cis retinol by RPE65. Finally, it is oxidized to 11-cis retinal before traveling back to the rod outer segment, where it can again be conjugated to an opsin to form a new functional rhodopsin. Many proteins involved in the chemical transformation and transport for retinoids are causative agents of RD. Mutations in the gene that encodes the retinal pigment epithelium-specific $65 \mathrm{kDa}$ protein (RPE65) can cause arRP or autosomalrecessive LCA (arLCA); $A B C A$ encodes a retinal ATPbinding cassette transporter, and mutations lead to a wide variety of clinical symptoms, including arRP, autosomalrecessive Stargardt disease and arCORD; the gene IRBP1 encodes the interphotoreceptor retinoid binding protein and mutations cause arRP; LRAT encodes lecithin retinol acyltransferase and mutations cause arRP and arLCA. Mutations in up to 13 different genes involved in the visual cycle lead to different retinal degenerations, highlighting the importance of this biochemical pathway in the physiology of vision. 
Table 4. Pathways related to retinal dystrophies

\begin{tabular}{|c|c|c|}
\hline Pathway & Genes causing retinal dystrophy & Phenotypes \\
\hline Phototransduction & CNGA1, CNGB1, GUCA1B, RHO, PDE6A, PDE6B, PDE6C, SAG, CNGB3 & adRP, arRP, adMD, dCSNB, Oguchi disease, arCORD \\
\hline Visual cycle & $\begin{array}{l}\text { ABCA4, RGR, RLBP1, BEST1, IRBP, RPE65, CA4, RDH12, IDH3B, ELOVL4, } \\
\text { PITPNM3, GUCY2D }\end{array}$ & $\begin{array}{l}\text { adRP, arRP, arMD, adMD, arCORD, adCORD, coroid } \\
\text { sclerosis, arLCA }\end{array}$ \\
\hline $\begin{array}{l}\text { Phagocytosis of rod outer } \\
\text { segments }\end{array}$ & MERTK & $\operatorname{arRP}$ \\
\hline Retinal development & CRX, NRL, NR2E3, SEMA4A, RAX2, PROM1, TSPAN12, TULP1, OTX2 & adRP, arRP, adLCA, arLCA, adCORD, adMD, FEVR \\
\hline Ciliary structure & $\begin{array}{l}\text { CEP290, RP1, USH2A, CRB1, RP2, RPGR, RPGRIP1, LCA5, OFD1, MYO7A, } \\
\text { USH1C, DFNB31, CDH23, PCDH15, USH1G, GPR98, BBS1-BBS10, TRIM32, } \\
\text { BBS12, BBS13, AHI1 }\end{array}$ & $\begin{array}{l}\text { adRP, arRP, xIRP, arLCA, JS, BBS, USH, x|CORD, xICSNB, } \\
\text { MKS, LGMD2H, MKKS }\end{array}$ \\
\hline Photoreceptor structure & RDS, ROM1, FSC2 & adRP, digenic RP, adMD \\
\hline mRNA splicing & HPRP3, PRPF8, PRPF31, PAP1, TOPORS & $\mathrm{adRP}$ \\
\hline Others & $\begin{array}{l}\text { ASCC3L1, SPATA7,EYS, KLHL7, RD3, KCNV2, RIMS1, CACNA2D4, ADAM9, } \\
\text { CNNM4, TRPM1, CABP4, OFD1 }\end{array}$ & adRP, arRP, arCOD, arLCA, adCORD, CORD, arCORD, JS \\
\hline
\end{tabular}

adCORD: autosomal-dominant cone and rod dystrophy; adLCA: autosomal dominant Leber's congenital amaurosis; adMD: autosomal-dominant macular dystrophy; adRP: autosomal-dominant retinitis pigmentosa; arCORD: autosomal-recessive cone and rod dystrophy; arCOD: autosomal recessive cone dystrophy; arLCA: autosomal-recessive Leber's congenital amaurosis; arMD: autosomal-recessive macular dystrophy; arRP: autosomal-recessive retinitis pigmentosa; BBS: Bardet-Biedl syndrome; CORD: cone and rod dystrophy; dCSNB: dominant congenital stationary night blindness; FEVR: familial exhudative vitreoretinopathy; JS: Joubert syndrome; LGMD2H: limb and griddle muscular dystrophy type 2H; MD: macular degeneration; MKKS: McKusick-Kaufmann syndrome; MKS: Meckel-Gruber syndrome; RdCVF: rod-derived cone viability factor; RP: retinitis pigmentosa; USH: Usher syndrome; xICORD: X-linked cone and rod dystrophy; xICSNB: X-linked congenital stationary night blindness; XIRP: X-linked retinitis pigmentosa.

Table 5. Genes and proteins leading to retinal dystrophies involved in phototransduction, visual cycle and phagocytosis of rod outer segments

\begin{tabular}{|c|c|c|c|c|c|}
\hline Gene & Location & Protein & Function & $\%$ & Type of RP \\
\hline CNGA1 & $4 p 12$ & rod cGMP-gated channel alpha subunit & Phototransduction & 2.2 & arRP \\
\hline CNGB1 & $16 q 13$ & rod cGMP-gated channel beta subunit & Phototransduction & & $\operatorname{arRP}$ \\
\hline GUCA1B & $6 \mathrm{p} 21.1$ & guanylate cyclase activating protein 1B & Phototransduction & & adRP, adMD \\
\hline RHO & $3 q 22.1$ & rhodopsin & Phototransduction & $19-25$ & adRP, arRP, dCSNB \\
\hline PDE6A & $5 q 33.1$ & cGMP phosphodiesterase alpha subunit & Phototransduction & 4 & $\operatorname{arRP}$ \\
\hline PDE6B & $4 q 16.3$ & cGMP phosphodiesterase beta subunit & Phototransduction & 4 & arRP, dCSNB \\
\hline PDE6C & $10 q 23.33$ & cone alpha subunit of cGMP phosphodiesterase & Phototransduction & & $\operatorname{arCOD}$ \\
\hline$S A G$ & $2 q 37.1$ & arrestin & Phototransduction & & arRP, Oguchi disease \\
\hline CNGB3 & $8 q 21.3$ & cone cyclic nucleotide-gated cation channel beta 3 subunit & Phototransduction & & $\operatorname{arCOD}$ \\
\hline ABCA4 & $1 \mathrm{p} 22.1$ & ATP-binding cassette transporter - retinal & Visual cycle & 2,9 & arRP, arMD, arCORD \\
\hline$R G R$ & $10 q 23.1$ & RPE-retinal G protein-coupled receptor & Visual cycle & 0,5 & arRP, coroid sclerosis \\
\hline RLBP1 & $15 q 26.1$ & retinaldehyde-binding protein 1 & Visual cycle & & $\operatorname{arRP}$ \\
\hline BEST1 & $11 q 12.3$ & Bestrophin-1 & Visual cycle & & adMD (Best type) \\
\hline IRBP & & & Visual cycle & & arRP \\
\hline RPE65 & $1 \mathrm{p} 31.2$ & retinal pigment epithelium-specific 65 kDa protein & Visual cycle & 2 & arRP, arLCA \\
\hline CA4 & $17 q 23.2$ & carbonic anhydrase IV & Visual cycle & & adRP \\
\hline RDH12 & $14 q 24.1$ & retinal dehydrogenase 12 & Visual cycle & 4 & $\operatorname{arRP}$ \\
\hline IDH3B & $20 \mathrm{p} 13$ & NAD(+)-specific isocitrate dehydrogenase 3 beta & Visual cycle & & $\operatorname{arRP}$ \\
\hline ELOVL4 & $6 q 14.1$ & elongation of very long fatty acids protein & Visual cycle & & adMD \\
\hline PITPNM3 & $17 p 13.2$ & phosphatidylinositol transfer membrane-associated family member 3 & Visual cycle & & adCORD \\
\hline LRAT & $4 q 32.1$ & lecithin retinol acyltransferase & Visual cycle & 0,7 & arRP, arLCA \\
\hline GUCY2D & 17p13.22 & retinal-specific guanylate cyclase 2D & visual cycle & 21 & arLCA, adCORD \\
\hline MERTK & $2 q 13$ & c-mer protooncogene receptor tyrosine kinase & Phagocytosis of ROS & 0,6 & arRP \\
\hline
\end{tabular}

adCORD: autosomal-dominant cone and rod dystrophy; adMD: autosomal-dominant macular dystrophy; adRP: autosomal-dominant retinitis pigmentosa; arCORD: autosomal-recessive cone and rod dystrophy; arCOD: autosonal recessive cone dystrophy; arLCA: autosomal-recessive Leber's congenital amaurosis; arMD: autosomalrecessive macular dystrophy; arRP: autosomal-recessive retinitis pigmentosa; ROS: reactive oxygen species. 
Table 6. Genes and proteins leading to retinal dystrophies involved in structure of photoreceptors and ciliary function

\begin{tabular}{|c|c|c|c|c|c|}
\hline Gene & Location & Protein & Function & $\%$ & Type of RP \\
\hline CEP290 & $12 q 21.32$ & centrosomal protein $290 \mathrm{kDa}$ & Structural: connecting cilium & 21 & $\operatorname{arRP}$, arLCA, JS, BBS \\
\hline FSC2 & $17 q 25.3$ & Fascin 2 & Structural & & $\mathrm{adRP}$ \\
\hline RDS & $6 p 21.2$ & Retinal degeneration slow-peripherin & Structural & 9.5 & $\begin{array}{l}\text { adRP, adMD, RP digenic } \\
\text { with ROM1 }\end{array}$ \\
\hline ROM1 & $11 q 12.3$ & retinal outer segment membrane protein 1 & Structural & 2 & RP digenic with RDS \\
\hline RP1 & $8 q 12.1$ & RP1 protein & Structural: photoreceptor trafficking & 3.5 & adRP, arRP \\
\hline TULP1 & $6 p 21.31$ & tubby-like protein 1 & Retinal development & 2 & $\operatorname{arRP}$, arLCA \\
\hline USH2A & $1 \mathrm{q} 41$ & usherin & Structural: photoreceptor trafficking & 10 & arRP, USH \\
\hline$C R B 1$ & $1 \mathrm{q} 31.3$ & crumbs homolog 1 & Structural: extracellular matrix & 6.5 & $\operatorname{arRP}, \operatorname{arLCA}$ \\
\hline$R P 2$ & Xp11.23 & XRP2 protein similar to human cofactor $C$ & Structural: photoreceptor trafficking & 15 & $x \mid R P$ \\
\hline$R P G R$ & Xp14 & retinitis pigmentosa GTPase regulator & Structural: photoreceptor trafficking & 75 & $x|R P, x| C O R D, x \mid C S N B$ \\
\hline RPGRIP1 & $14 q 11.2$ & RP GTPase regulator-interacting protein 1 & Structural: photoreceptor trafficking & & $\operatorname{arLCA}$ \\
\hline LCA5 & $6 q 14.1$ & Lebercilin & Structural: photoreceptor trafficking & & $\operatorname{arLCA}$ \\
\hline OFD1 & Xp22.2 & oral-facial-digital syndrome 1 protein & Ciliary function & & JS \\
\hline MYOTA & $11 q 13.5$ & Myosin VIIA & Photoreceptor trafficking & & USH \\
\hline USHIC & 11p14-p15 & harmonin & Structural: scaffolding & & USH \\
\hline DFNB31 & $9 q 32-q 34$ & whirlin & Structural: scaffolding & & USH \\
\hline $\mathrm{CDH} 23$ & $10 q 21-q 22$ & cadherin-23 & Structural: cell-cell adhesion & & USH \\
\hline PCDH15 & $10 q 21-q 22$ & protocadherin-15 & Structural: cell-cell adhesion & & USH \\
\hline USHIG & $17 q 24-q 25$ & SANS & Structural: scaffolding & & USH \\
\hline GPR98 & $5 q 14-q 21$ & VLGR1 & Structural: extracellular matrix & & USH \\
\hline BBS1 & $11 q 13$ & BBS protein 1 & Ciliary function & & BBS \\
\hline BBS2 & $16 \mathrm{q} 21.2$ & BBS protein 2 & Ciliary function & & BBS \\
\hline ARL6/BBS3 & $3 q 11.2$ & ADP-ribosylation factor-like 6 & Ciliary function & & BBS \\
\hline BBS4 & $15 q 24.1$ & BBS protein 4 & Ciliary function & & BBS \\
\hline BBS5 & $2 q 31.1$ & flagellar apparatus-basal body protein DKFZp7621194 & Ciliary function & & BBS \\
\hline MKKS/BBS6 & 20p12.1 & McKusick-Kaufman syndrome protein & Ciliary function: chaperonine & & BBS, MKKS \\
\hline BBS7 & $4 \mathrm{q} 27$ & BBS protein 7 & Ciliary function & & BBS \\
\hline TTC8/BBS8 & $14 q 32.11$ & tetratricopeptide repeat domain 8 & Ciliary function & & BBS \\
\hline B1/BBS9 & $7 p 14.3$ & parathyroid hormone-responsive B1 protein & Ciliary function & & BBS \\
\hline BBS10 & $12 q 21.2$ & BBS protein 10 & Ciliary function: chaperonine & & BBS \\
\hline TRIM32 & $9 q 33.1$ & tripartite motif-containing protein 32 & Ciliary function & & BBS, LGMD2H \\
\hline BBS12 & $4 q 27$ & BBS protein 12 & Ciliary function: chaperonine & & BBS \\
\hline MKS1/BBS13 & $17 q 22$ & FABB proteome-like protein & Ciliary function & & BBS, MKS \\
\hline AHI1 & $6 q 23.3$ & Abelson helper integration site 1 & Ciliary function & & $\mathrm{NPH}$ \\
\hline
\end{tabular}

adMD: autosomal-dominant macular dystrophy; adRP: autosomal-dominant retinitis pigmentosa; arLCA: autosomal-recessive Leber's congenital amaurosis; arRP: autosomal-recessive retinitis pigmentosa; BBS: Bardet-Biedl syndrome; CORD: cone and rod dystrophy; JS: Joubert syndrome; LGMD2H: limb and griddle muscular dystrophy type 2H; MKKS: McKusick-Kaufmann syndrome; MKS: Meckel-Gruber syndrome; NPH: Nephrohophthisis;:RP: retinitis pigmentosa; USH: Usher syndrome; XICORD: X-linked cone and rod dystrophy; xICSNB: X-linked congenital stationary night blindness; XIRP: X-linked retinitis pigmentosa.

\section{Phagocytosis of photoreceptor discs}

The stacks of discs containing visual pigment molecules in the outer segments of the photoreceptors are constantly renewed. New discs are added at the base of the outer segment at the cilium, and old discs are displaced up the outer segment and engulfed by the apical processes of the pigment epithelium. They are then broken down by lysis. Photoreceptor outer-segment discs are phagocytosed by the pigment epithelium in a diurnal cycle. Among the different proteins involved in this process, only MERTK, the gene encoding c-mer proto-oncogene receptor tyrosine kinase, has been identified as causing arRP. 
Table 7. Genes and proteins leading to retinal dystrophies involved in retinal development, mRNA splicing and other functions

\begin{tabular}{|c|c|c|c|c|c|}
\hline Gene & Location & Protein & Function & $\%$ & Type of RP \\
\hline KCNV2 & $9 p 24.2$ & potasium channel subfamily $\vee$ member 2 & lon interchange & & $\operatorname{arCOD}$ \\
\hline IMPDH1 & $7 q 32.1$ & inosine monophosphate dehydrogenase 1 & Nucleotide biosynthesis & 2.5 & $\operatorname{adRP}, \operatorname{adLCA}$ \\
\hline $\begin{array}{l}\text { CRX } \\
\text { arLCA, adCO }\end{array}$ & $\begin{array}{l}19 q 13.32 \\
\text { DRD }\end{array}$ & cone-rod otx-like photoreceptor homeobox transcription factor & Retinal development & 1 & adRP, adLCA, \\
\hline NRL & $14 q 11.2$ & neural retina leucine zipper & Retinal development & 0.7 & adRP, arRP \\
\hline NR2E3 & $15 q 23$ & nuclear receptor subfamily 2 group E3 & Retinal development & & $\operatorname{arRP}$ \\
\hline EYS & $6 q 12$ & eyes shut/spacemaker (Drosophila) homolog & Unknown & & arRP \\
\hline HPRP3 & $1 \mathrm{q} 21.3$ & human homolog of yeast pre-mRNA splicing factor 3 & mRNA splicing & 1 & adRP \\
\hline PRPF8 & 17p13.3 & human homolog of yeast pre-mRNA splicing factor C8 & mRNA splicing & 3 & $\operatorname{adRP}$ \\
\hline PRPF31 & $19 q 13.42$ & human homolog of yeast pre-mRNA splicing factor 31 & mRNA splicing & 8 & $\operatorname{adRP}$ \\
\hline PROM1 & $4 p 15.32$ & Prominin & Photoreceptor discs development & & adCORD, adMD \\
\hline SNRNP200 & $2 q 11.2$ & small nuclear ribonucleoprotein 200kDa & mRNA splicing & & $\operatorname{adRP}$ \\
\hline KLHL7 & $7 p 15.3$ & kelch-like 7 protein (Drosophila) & Protein degradation & & $\operatorname{adRP}$ \\
\hline TOPORS & $9 p 21.1$ & topoisomerase I binding arginine/serine rich protein & mRNA splicing & 1 & $\operatorname{adRP}$ \\
\hline RD3 & $1 q 32.3$ & protein: RD3 protein & Unknown & & $\operatorname{arLCA}$ \\
\hline RAX2 & $19 p 13.3$ & retina and anterior neural fold homeobox 2 transcription factor & Retina development & & CORD \\
\hline SEMA4A & $1 \mathrm{q} 22$ & Semaphorin 4A & Neuronal development & & adCORD \\
\hline RIMSI & $6 \mathrm{p} 13$ & regulating synaptic membrane exocytosis protein & Ribbon synapse trafficking & & adCORD \\
\hline CACNA2D4 & $12 p 13.33$ & calcium channel, voltage-dependent, alpha 2/delta subunit 4 & Ribbon synapse trafficking & & $\operatorname{arCOD}$ \\
\hline CERKL & $2 q 31.3$ & ceramide kinase-like protein & & & arRP \\
\hline AIPL1 & $17 q 13.2$ & arylhydrocarbon-interacting receptor protein-like 1 & Chaperone & 3.4 & $\operatorname{arLCA}$, adCORD \\
\hline PAP1 & $7 p 14.3$ & PIM-1 kinase & mRNA splicing & & adRP \\
\hline ADAM9 & $8 p 11.23$ & ADAM metallopeptidase domain 9 (meltrin gamma) protein & Structural: adhesion molecule & & CORD \\
\hline CNNM4 & $2 q 11.2$ & cyclin M4 & Neural retina function & & Jalili synd. \\
\hline TRPM1 & $15 q 13.3$ & $\begin{array}{l}\text { transient receptor potential cation channel, subfamily M, } \\
\text { member } 1 \text { (melastatin) }\end{array}$ & Light-evoked response of the inner & tina & adCSNB \\
\hline SPATA7 & $14 q 31.3$ & spermatogenesis associated protein 7 & Unknown & & $\operatorname{arLCA}$, arRP \\
\hline TSPAN12 & 7q31.31 & tetraspanin 12 & Retinal development & & FEVR \\
\hline OTX2 & $14 q 22.3$ & orthodenticle homeobox 2 protein & Retinal development & & $\operatorname{adLCA}$ \\
\hline ASCC3L1 & $2 q 11.2$ & activating signal cointegrator 1 complex subunit 3-like 1 & Unknown & & $\operatorname{adRP}$ \\
\hline CABP4 & $11 \mathrm{q} 13.1$ & calcium binding protein 4 & Synapsis function & & $\operatorname{arCORD}$ \\
\hline USH3A & $3 q 21-q 25$ & clarin-1 & Ribbon synapse trafficking & & USH \\
\hline
\end{tabular}

adCORD: autosomal-dominant cone and rod dystrophy; adCSNB: autosomal dominant congenital stationary night blindness adLCA: autosomal dominant Leber's congenital amaurosis; adMD: autosomal-dominant macular dystrophy; adRP: autosomal-dominant retinitis pigmentosa; arCOD: autosomal recessive cone dystrophy; arCORD: autosomal-recessive cone and rod dystrophy; arLCA: autosomal-recessive Leber's congenital amaurosis; arRP: autosomal-recessive retinitis pigmentosa; CORD: cone and rod dystrophy; FEVR: familial exhudative vitreoretinopathy; RP: retinitis pigmentosa; USH: Usher syndrome.

\section{Retinal development}

Retinal cells are specialized neurons structured in layers. Their patterns of connectivity are crucial, and the correct development of these cells is essential for retinal function. This development is regulated by the precise expression of genes in the right cell type and at the right time, and this regulation is mediated by the synergistic/antagonistic action of a limited number of transcription factors. Mutations in the cone-rod otx-like photoreceptor homeobox transcription factor (encoded by the gene
CRX) are responsible for adRP, adLCA, arLCA and adCORD; mutations in the neural retina leucine zipper (encoded by the gene NRL) can lead to adRP and arRP. Mutations in the gene encoding the tubby-like protein 1 (TULP1) can cause recessive RP or LCA. RAX2 encodes the retina and anterior neural fold homeobox 2 transcription factor, and mutations are responsible for CORD. Mutations in NR2E3 encoding the nuclear receptor subfamily 2 group E3 cause arRP or adRP. 
Mutations in the genes encoding prominin (PROM1) and semaphorin 4A (SEMA4A) lead to adCORD. OTX2 (encoding orthodenticle homeobox 2 protein) mutations are associated with adLCA. Finally, defects in TSPAN12 (tetraspanin 12) are associated with familial exudative vitreoretinopathy.

\section{Photoreceptor structure}

Although the majority of RD phenotypes appear to result from defects at a single genetic locus, at least one form of $\mathrm{RP}$ appears to require co-inheritance of defects in the unlinked genes $R D S$, which encodes peripherin/RDS, and ROM1, which encodes retinal outer-segment membrane protein 1 . These proteins are components of the polypeptide subunits of an oligomeric transmembrane protein complex, which is present at photoreceptor outer-segment disc rims and is essential for the correct incidence of light into the discs.

Another protein, fascin 2, encoded by $F S C 2$, appears to play a role in the assembly or stabilization of inner segment and calycal process actin filament bundles in photoreceptors and probably regulates the inner segment actin cytoskeleton.

\section{Ciliary structure and function}

Photoreceptors have an inner segment that contains the cell organelles and an outer segment composed almost exclusively of optic discs. The connecting cilium connects the inner and outer segments. These discs are constantly renewed and a high number of molecules must travel from the inner segment to the outer segment through the connecting cilium. The development and architecture of the connecting cilium, the correct folding of the involved proteins and the links between the cilium and its surrounding region (calycal process, extracellular matrix) have been shown to be essential for retinal function. Furthermore, as cilia are specialized structures present in many other tissues, defects in the protein components of the cilia and chaperones involved in their development can cause not only isolated RD but also conditions that include RD among their symptoms, such as USH or BBS. Recently, it has been demonstrated that some ciliary proteins act as positive or negative phenotypic modifiers on defects in other proteins. Some examples are: USH2A, which encodes the large extracellular protein usherin, and defects are responsible for arRP and USH; the genes USH1C and DFNB31, which encode the scaffolding proteins harmonin and whirlin; and $\mathrm{CDH} 23$ and PCDH15, which encode the cell-cell adhesion proteins cadherin 23 and protocadherin 15, respectively.

\section{mRNA splicing}

Pre-mRNA splicing is a critical step in mammalian gene expression. Mutations in genes involved in the splicing processes or spliceosome are associated with a wide range of human diseases, including those involving the retina. Among the genes involved in mRNA splicing, mutations in PRPC8 (human homolog of yeast premRNA splicing factor C8), PRP31 (human homolog of yeast pre-mRNA splicing factor 31), HPRP3 (human homolog of yeast pre-mRNA splicing factor 3), PAP-1 (PIM-1 kinase), TOPORS (topoisomerase-I-binding arginine/serine-rich protein) and SNRNP200 (small nuclear ribonucleoprotein, $200 \mathrm{kDa}$ ) are associated with adRP [14-18], although the mechanisms behind the process remain unclear.

\section{Other functions}

Many other genes and proteins are associated with RD. These proteins have a wide spectrum of functions, such as degradation of proteins in the retinal pigmented epithelium (RPE), ionic interchange, trafficking of molecules in the ribbon synapse of photoreceptors and many others. In addition, the functions of some proteins that have been associated with RD are still unknown.

\section{Molecular diagnosis in retinal dystrophies}

The first step toward the diagnosis of RD at the molecular level is genotyping; this allows a more precise prognosis of the possible future clinical evolution of RD, and it can be followed by genetic counseling. Moreover, genetic testing is crucial for the inclusion in human gene-specific clinical trials aimed at photoreceptor rescue. However, genetic and phenotypic heterogeneity limit mutation detection, rendering molecular diagnosis very complex. While sequencing remains the gold standard, this is costly and time consuming, and so alternative diagnostic approaches have been recently implemented.

One such alternative diagnostic approach is the use of microarray platforms to detect RP mutations. The most widely used are the specific-disease chips for different types of RD. They contain the previously identified mutations on the responsible known genes Identification rates (identifying at least one disease-associated mutation) depend on the geographical origin and ethnicity of the patient, and they currently stand at 47 to $78 \%$ for Stargardt disease [19-23], 28 to $40 \%$ for CORD [21, 23, $24,25], 28$ to $46 \%$ for LCA [26,-30], $45 \%$ for USH 1, and $26 \%$ for USH $2[31,32]$. These represent inexpensive and rapid first-step genetic testing tools for patients with a specific RD diagnosis.

In addition, other high-throughput DNA sequencing platforms targeted to hundreds of genes are being developed. They have been designed to contain either genes limited to exons [33] or full-length retinal disease genes, including introns, promoter regions or both [34]. Other chip-based co-segregation analyses for autosomalrecessive forms and LCA have also been designed, but 
these analyses requires the inclusion of samples from all the members of the family, both healthy and affected $[35,36]$.

Indirect genetic tools for linkage analysis and/or homozygosity mapping are also being used for RD genotyping, mainly for research purposes. However, increasing availability and low costs have made homozygosity mapping a particularly appealing approach for the molecular diagnosis of RD [37].

The analytical validity of these procedures has been proved. However, their clinical validity remains to be established for every ethnic group, specific array and type of retinal disease. Clinical applications are also somewhat limited due to the fact that many RP genes are still unknown, and mutations may lie outside of commonly tested regions.

\section{Perspectives for future therapeutics}

Currently, optical and electronic devices are the only tools available to improve vision in some patients with RD. In the majority of cases, there are no effective therapies available to prevent, stabilize or reverse monogenic RD.

A key goal in developing an effective therapy for RD is the understanding of its pathophysiology, and the identification of the molecular events and disease mechanisms occurring in the degenerative retina. Based on advances in knowledge about these processes, several novel therapeutic strategies are currently being evaluated, including pharmacological treatments, gene therapy and cell therapy.

RD disorders are initiated by mutations that affect rod and/or cone photoreceptors and cause subsequent degeneration and cellular death. Consequently, therapeutic strategies are focused on targeting the specific genetic disorder (gene therapy), slowing or stopping photoreceptor degeneration or apoptosis (growth factors or calcium-blocker applications, vitamin supplements, endogenous cone viability factors), or even the replacement of lost cells (transplantation, use of stem or precursor cells).

Before these strategies can be applied to humans, animal models, preclinical studies and appropriately designed human clinical trials are needed to test different treatments and provide information on their safety and efficacy. According to the ClinicalTrials.gov database, 44 interventional clinical trials for RP have been or are being carried out [38].

\section{Pharmacological therapies}

Developing an effective pharmacological therapy for RD must be based on the knowledge of the molecular events and major disease mechanisms and the extent to which they overlap. Current therapies target these pathogenic mechanisms.

\section{Vitamin supplementation and chaperone treatments}

Results from experimental effects on animal models [39] and a randomized controlled double-masked clinical trial [40] have suggested possible clinical benefits of vitamin A supplementation in RP. However, the use of these supplements in other genetic forms of $\mathrm{RD}$, such as ABCA4-related diseases (arRP, arCORD, and autosomalrecessive Stargardt $\mathrm{MD}$ ), may accelerate the accumulation of toxic lipofuscin pigments in the retinal pigment epithelium, and thus worsen photoreceptor degeneration. As a result, avoidance of vitamin A supplementation is recommended for people with Stargardt disease.

Another viable approach to RP therapy is the use of pharmacological chaperones [41]. Pharmacological chaperones target protein structure, while chaperone inducers (for example, geldanamycin, radicicol and 17-AAG) and autophagy inducers (for example, rapamycin) stimulate degradation, manipulating the cellular quality control machinery. Some studies have suggested that the rod opsin chromophore (11-cis retinal) and retinal analogues (for example, 9-cis retinal) can act as pharmacological chaperones, whereas rapamycin is effective against the toxic gain of function, but not the dominant-negative effects of mutant rod opsin [41].

\section{Anti-apoptotic therapy and neuroprotection: endogenous cone viability factors and growth factors}

The key goals in pharmacological therapy for RD are neuroprotection and the inhibition of pro-apoptotic pathways, or the activation of endogenous anti-apoptotic signaling systems [42]. Neuroprotection of photoreceptor cells is primarily targeted at structural preservation, and also preventing loss of function. The neuroprotective factors include one 'survival' factor (rod-derived cone viability factor (RdCVF)) and four different neurotrophic factors (ciliary neurotrophic factor, basic fibroblast growth factor, brain-derived neurotrophic factor and nerve growth factor) that delay rod degeneration in some animal models of RP [43].

RdCVF is a protein that increases cone survival. Injections of this protein in p.P23H rats induced an increase in cone cell number and a further increase in the electroretinogram, indicating that RdCVF can not only rescue cones but can also significantly preserve their function [44].

Ciliary neurotrophic factor has shown efficacy in different animal models, and has progressed to phase II/ III clinical trials in early-stage and late-stage RP [45]. It has been administered by encapsulated cell technology, which allows the controlled, continuous and long-term administration of protein drugs in the eye, where the therapeutic agents are needed, and does not subject the host to systemic exposure [46]. 


\section{Gene-based therapy}

Many RD-associated genes have been identified and their functions elucidated. Over the past decade, there has been a substantial effort to develop gene therapy for inherited retinal degeneration, culminating in the recent initiation of clinical trials.

A variety of monogenic recessive disorders could be amenable to treatment by gene replacement therapy through the delivery of healthy copies of the defective gene via replication-deficient viral vectors $[47,48]$. Preliminary results from three clinical trials indicate that the treatment of a form of LCA by gene therapy can be safe and effective. Phase I clinical trials of gene therapy targeting the gene RPE65 [49-51] are being conducted in three different medical centers: Moorfields Eye Hospital, UK [49], the Children's Hospital of Philadelphia, USA, [51], and the Universities of Pennsylvania and Florida, USA. [50],

For some autosomal-dominant forms of RP or LCA, in which expression of a mutant allele has a gain-offunction effect on photoreceptor cells, or a dominantnegative mechanism or a combination of both, gene therapy is likely to depend on efficient silencing of the mutated allele [52]. Gene-silencing strategies for these conditions include RNA interference by microRNAbased hairpins (Prph2 animal model), short hairpin RNAs (IMPDH1 gene murine model), RNA interference by microRNA combined with gene replacement (transgenic mouse simulating human RHO-adRP), and antisense oligonucleotide technologies.

\section{Cell therapy}

Adult stem cells isolated from the retinal pigment epithelium at the ciliary body margin can differentiate into all retinal cell types, including photoreceptors, bipolar cells and Müller glia. Animal experiments have shown that, in response to environmental cues, they can repopulate damaged retinas, regrow neuronal axons, repair higher cortical pathways, and restore pupil reflexes, light responses and basic pattern recognition. When transplanted into a damaged retina, the progenitor cells integrate with the retina, forming a protective layer that preserves existing cells and increases photoreceptor density - that is, neurogenesis can be fostered by recruitment of endogenous stem cells into damaged areas or by transplanted stem cells [53].

Clinical trials using human fetal neural retinal tissue and retinal pigment epithelium cells and adult stem cells are in progress. A phase I clinical trial to repair damaged retinas in 50 patients with RP and age-related macular degeneration has been conducted in India. Phase I clinical trials to repair damaged retinas in patients with RP degeneration have been conducted using autologous stem cells derived from bone marrow, injected either near the cornea or intravitreally (ClinicalTrials.gov NCT01068561). Preliminary results have shown visual improvement.

Additionally, a non-invasive cell-based therapy consisting of systemic administration of pluripotent bone-marrow-derived mesenchymal stem cells to rescue vision and associated vascular pathology has been tested in an animal model for RP, resulting in preservation of both rod and cone photoreceptors and visual function [54]. These results underscore the potential application of mesenchymal stem cells in treating retinal degeneration.

\section{Concluding remarks}

To date, more than 200 genes associated with RD have been identified; they are involved in many different clinical entities such as RCA, LCA, USH, CORD and $\mathrm{MD}$. The most surprising outcome of these findings is the exceptional heterogeneity involved: a high number of disease-causing mutations have been detected in most RD genes, mutations in many different genes can cause the same disease, and different mutations in the same gene may cause different diseases. This genetic heterogeneity underlies a high clinical variability, even among family members with the same mutation. The RD genes involve many different pathways, and expression ranges from very limited (for example, expressed in rod photoreceptors only) to ubiquitous.

Gaining knowledge of the genetic causes and pathways involved in the photoreceptor degeneration underlying these disorders is the first step in implementing the correct clinical management and a possible prevention or cure for the disease.

An increasing number of clinical trials are exploring different therapeutic approaches with the aim of treating inherited retinal dystrophies. Phenotypic characterization and genotyping are crucial in order to provide patients with potential personalized treatment. Further research into the mechanisms underlying photoreceptor degeneration and retinal cell apoptosis should also bring us closer to the goal of developing efficient and safe therapies.

\section{Abbreviations}

ad: autosomal dominant; adCORD: autosomal-dominant cone and rod dystrophy; adLCA: autosomal dominant LCA; adMD: autosomal-dominant macular dystrophy; adRP: autosomal-dominant retinitis pigmentosa; ar: autosomal-recessive; arCORD: autosomal-recessive cone and rod dystrophy; arLCA: autosomal-recessive LCA; arMD: autosomal-recessive macular dystrophy; arRP: autosomal-recessive retinitis pigmentosa; BBS: Bardet-Bied syndrome; CORD: cone and rod dystrophy; dCSNB: dominant congenital stationary night blindness; FEVR: familial exhudative vitreoretinopathy; IS: Joubert syndrome; LCA: Leber's congenital amaurosis; LGMD2H: limb and griddle muscular dystrophy type $2 \mathrm{H}$; MD: macular degeneration; MKKS McKusick-Kaufmann syndrome; MKS: Meckel-Gruber syndrome; RD: retinal dystrophy; RdCVF: rod-derived cone viability factor; ROS: reactive oxygen species; RP: retinitis pigmentosa; USH: Usher syndrome; $x$ : X-linked; $x$ ICORD: $X$-linked cone and rod dystrophy; XICSNB: $X$-linked congenital stationary night blindness; XIRP: X-linked retinitis pigmentosa. 


\section{Competing interests}

The authors declare that they have no competing interests.

\section{Authors' contributions}

CA designed the overall layout and different sections of the article, and wrote the first draft of the manuscript. JM performed a thorough review of the manuscript, and provided the descriptions of the candidate genes and pathways, and the genetic patterns. Both authors reviewed and approved the final manuscript.

\section{Acknowledgements}

We wish to acknowledge Retina España, FAARPEE (Federación de Asociaciones de Afectados de Retinosis Pigmentaria del Estado Español) CIBERER (Network Biomedical Centre of Research on Rare Diseases) and ISCIII (The Institute of Health Carlos III from the Spanish Ministry of Science and Innovation).

\section{Author details}

'Department of Medical Genetics, IIS-Fundación Jiménez Díaz/CIBERER, Av/ Reyes Católicos no. 2; 28040, Madrid, Spain. Unidad de Genética, Hospital Universitario La Fe/CIBERER, Avda. Campanar, 21, 46009 Valencia, Spain.

Published: 27 May 2010

\section{References}

1. Ammann F, Klein D, Franceschetti A: Genetic and epidemiological investigations on pigmentary degeneration of the retina and allied disorders in Switzerland. J Neurol Sci 1965, 2:183-196.

2. Boughman JA, Conneally PM, Nance WE: Population genetic studies of retinitis pigmentosa. Am J Hum Genet 1980, 32:223-235.

3. Jay M: On the heredity of retinitis pigmentosa. Br J Ophthalmol 1982, 66:405-416.

4. Haim M: Epidemiology of retinitis pigmentosa in Denmark. Acta Ophthalmol Scand Suppl 2002, 233 (Suppl):1-34.

5. Sen P, Bhargava A, George R, Ve Ramesh S, Hemamalini A, Prema R, Kumaramanickavel G, Vijaya L: Prevalence of retinitis pigmentosa in South Indian population aged above 40 years. Ophthalmic Epidemiol 2008, 15:279-281.

6. $\mathrm{Xu}$ L, Hu L, Ma K, Li J, Jonas JB: Prevalence of retinitis pigmentosa in urban and rural adult Chinese: The Beijing Eye Study. Eur J Ophthalmol 2006 16:865-866

7. Daiger SP, Bowne SJ, Sullivan LS: Perspective on genes and mutations causing retinitis pigmentosa. Arch Ophthalmol 2007, 125:151-158.

8. Riveiro-Alvarez R, Valverde D, Lorda-Sanchez I, Trujillo-Tiebas MJ, Cantalapiedra D, Vallespin E, Aguirre-Lamban J, Ramos C, Ayuso C: Partial paternal uniparental disomy (UPD) of chromosome 1 in a patient with Stargardt disease. Mol Vis 2007, 13:96-101.

9. Ayuso C, García-Sandoval B, Nájera C, Valverde D, Carballo M, Antiñolo G: Retinitis pigmentosa in Spain. The Spanish multicentric and multidisciplinary group for research into retinitis pigmentosa. Clin Genet 1995, 48:120-122.

10. Moriaux F, Hamedani M, Hurbli T, Utreza Y, Oubaaz A, Morax S: Waardenburg's syndrome. J Fr Ophtalmol 1999, 22:799-809.

11. Schuster A, Weisschuh N, Jagle H, Besch D, Janecke AR, Zirler H, Tippmann S, Zrenner E, Wissinger B: Novel rhodopsin mutations and genotypephenotype correlation in patients with autosomal dominant retinitis pigmentosa. Br J Ophthalmol 2005, 89:1258-1264.

12. Dryja TP, McGee TL, Hahn LB, Cowley GS, Olsson JE, Reichel E, Sandberg MA, Berson EL: Mutations within the rhodopsin gene in patients with autosomal dominant retinitis pigmentosa. N Engl J Med 1990, 323:1302-1307.

13. RetNet: Retinal Information Network [http://www.sph.uth.tmc.edu/Retnet/]

14. McKie AB, McHale JC, Keen TJ, Tarttelin EE, Goliath R, van Lith-Verhoeven JJ, Greenberg J, Ramesar RS, Hoyng CB, Cremers FP, Mackey DA, Bhattacharya SS, Bird AC, Markham AF, Inglehearn CF: Mutations in the pre-mRNA splicing factor gene PRPC8 in autosomal dominant retinitis pigmentosa (RP13). Hum Mol Genet 2001, 10:1555-1562.

15. Vithana EN, Abu-Safieh L, Allen MJ, Carey A, Papaioannou M, Chakarova C, Al-Maghtheh M, Ebenezer ND, Willis C, Moore AT, Bird AC, Hunt DM, Bhattacharya SS: A human homolog of yeast pre-mRNA splicing gene, PRP31, underlies autosomal dominant retinitis pigmentosa on chromosome 19q13.4. Mol Cell 2001, 8:375-381.
16. Chakarova CF, Papaioannou MG, Khanna H, Lopez I, Waseen N, Shah A Theis T, Friedman J, Maubaret C, Bujakowska K, Veraitch B, Abd El-Aziz MM, Prescott de Q, Parapuram SK, Bickmore WA, Munro PM, Gal A, Hamel CP, Marigo V Ponting CP, Wissinger B, Zrenner E, Matter K, Swaroop A, Koenekoop RK, Bhattacharya SS: Mutations in TOPORS cause autosomal dominant retinitis pigmentosa with perivascular retinal pigment epithelium atrophy. $\mathrm{Am} \mathrm{J}$ Hum Genet 2007, 81:1098-1103.

17. Maita H, Kitaura H, Keen TJ, Inglehearn CF, Ariga H, Iguchi-Ariga SM: PAP-1, the mutated gene underlying the RP9 form of dominant retinitis pigmentosa, is a splicing factor. Exp Cell Res 2004, 300:283-296.

18. Zhao C, Bellur DL, Lu S, Zhao F, Grassi MA, Bowne SJ, Sullivan LS, Daiger SP, Chen LI, Pang CP, Zhao K, Staley JP, Larsson C: Autosomal-dominant retinitis pigmentosa caused by a mutation in SNRNP200, a gene required for unwinding of U4/U6 snRNAs. Am J Hum Genet 2009, 85:617-627.

19. Jaakson K, Zernant J, Külm M, Hutchinson A, Tonisson N, Glavac D, RavnikGlavac M, Hawlina M, Meltzer MR, Caruso RC, Testa F, Maugeri A, Hoyng CB, Gouras P, Simonelli F, Lewis RA, Lupski JR, Cremers FP, Allikmets R: Genotyping microarray (gene chip) for the $A B C R(A B C A 4)$ gene. Hum Mutat 2003, 22:395-403.

20. Stenirri S, Alaimo G, Manitto MP, Brancato R, Ferrari M, Cremonesi L: Are microarrays useful in the screening of ABCA4 mutations in Italian patients affected by macular degenerations? Clin Chem Lab Med 2008, 46:1250-1255.

21. Aguirre-Lamban J, Riveiro-Alvarez R, Maia-Lopes S, Cantalapiedra D, Vallespin E, Avila-Fernandez A, Villaverde-Montero C, Trujillo-Tiebas MJ, Ramos C, Ayuso C: Molecular analysis of the ABCA4 gene for reliable detection of allelic variations in Spanish patients: identification of 21 novel variants. Br J Ophthalmol 2009, 93:614-621.

22. Maia Lopes S, Aguirre Lamban J, Castelo Branco M, Riveiro Alvarez R, Ayuso C, Silva ED: $A B C A 4$ mutations in Portuguese Stargardt patients: identification of new mutations and their phenotypic analysis. Mol Vis 2009, 15:584-591.

23. Ernest PJ, Boon CJ, Klevering BJ, Hoefsloot LH, Hoyng CB: Outcome of ABCA4 microarray screening in routine clinical practice. Mol Vis 2009, 15:2841-2847.

24. Klevering BJ, Yzer S, Rohrschneider K, Zonneveld M, Allikmets R, van den Born $\mathrm{LI}$, Maugeri A, Hoyng CB, Cremers FP: Microarray-based mutation analysis of the $A B C A 4$ ( $A B C R$ ) gene in autosomal recessive cone-rod dystrophy and retinitis pigmentosa. Eur J Hum Genet 2004, 12:1024-1032.

25. Valverde D, Riveiro-Alvarez $R$, Aguirre-Lamban J, Baiget M, Carballo M, Antiñolo G, Millán JM, Garcia Sandoval B, Ayuso C: Spectrum of the ABCA4 gene mutations implicated in severe retinopathies in Spanish patients. Invest Ophthalmol Vis Sci 2007, 48:985-990.

26. Zernant J, Külm M, Dharmaraj S, den Hollander Al, Perrault I, Preising MN, Lorenz B, Kaplan J, Cremers FP, Maumenee I, Koenekoop RK, Allikmets R: Genotyping microarray (disease chip) for Leber congenital amaurosis: detection of modifier alleles. Invest Ophthalmol Vis Sci 2005, 46:3052-3059.

27. Yzer S, Leroy BP, De Baere E, de Ravel TJ, Zonneveld MN, Voesenek K, Kellner U, Ciriano JP, de Faber JT, Rohrschneider K, Roepman R, den Hollander Al, Cruysberg JR, Meire F, Casteels I, van Moll-Ramirez NG, Allikmets R, van den Born LI, Cremers FP: Microarray-based mutation detection and phenotypic characterization of patients with Leber congenital amaurosis. Invest Ophthalmol Vis Sci 2006, 47:1167-1176.

28. Vallespin E, Cantalapiedra D, Riveiro-Alvarez R, Wilke R, Aguirre-Lamban J, Avila-Fernandez A, Lopez-Martinez MA, Gimenez A, Trujillo-Tiebas MJ, Ramos C, Ayuso C: Mutation screening of 299 Spanish families with retinal dystrophies by Leber congenital amaurosis genotyping microarray. Invest Ophthalmol Vis Sci 2007, 48:5653-5661.

29. Henderson RH, Waseem N, Searle R, van der Spuy J, Russell-Eggitt I, Bhattacharya SS, Thompson DA, Holder GE, Cheetham ME, Webster AR, Moore AT: An assessment of the apex microarray technology in genotyping patients with Leber congenital amaurosis and early-onset severe retinal dystrophy. Invest Ophthalmol Vis Sci 2007, 48:5684-5689.

30. Simonelli F, Ziviello C, Testa F, Rossi S, Fazzi E, Bianchi PE, Fossarello M, Signorini S, Bertone C, Galantuomo S, Brancati F, Valente EM, Ciccodicola A, Rinaldi E, Auricchio A, Banfi S: Clinical and molecular genetics of Leber's congenital amaurosis: a multicenter study of Italian patients. Invest Ophthalmol Vis Sci 2007, 48:4284-4290.

31. Cremers FPM, Kimberling WJ, Kulm M, de Brouwer AP, van Wijk E, te Brinke $H$, Cremers CWRJ, Hoefsloot LH, Banfi S, Simonelli F, Fleischhauer JC, Berger W, Kelley PM, Haralambous E, Bitner-Glindzicz M, Webster AR, Saihan Z, Debaere E, Leroy BP, Silvestri G, Mckay G, Koenekoop RK, Millan JM, Rosenberg T, Joensuu T, Sankila EM, Weil D, Weston MD, Wissinger B, Kremer H: 
Development of a genotyping microarray for Usher syndrome. J Med Genet 2007, 44:153-160.

32. Jaijo T, Aller E, García-García G, Aparisi MJ, Bernal S, Avila-Fernández A, Barragán I, Baiget M, Ayuso C, Antiñolo G, Díaz-Llopis M, Külm M, Beneyto M, Nájera C, Millán JM: Microarray-based mutation analysis of 183 Spanish families with Usher syndrome. Invest Ophthalmol Vis Sci 2010, 51:1311-1317.

33. Mandal MN, Heckenlively JR, Burch T, Chen L, Vasireddy V, Koenekoop RK, Sieving PA, Ayyagari R: Sequencing arrays for screening multiple genes associated with early-onset human retinal degenerations on a highthroughput platform. Invest Ophthalmol Vis Sci 2005, 46:3355-3362.

34. Daiger SP, Sullivan LS, Bowne SJ, Birch DG, Heckenlively JR, Pierce EA, Weinstock GM: Targeted high-throughput DNA sequencing for gene discovery in retinitis pigmentosa. Adv Exp Med Biol 2010, 664:325-331.

35. Pomares E, Marfany G, Brión MJ, Carracedo A, Gonzàlez-Duarte R: Novel high-throughput SNP genotyping cosegregation analysis for genetic diagnosis of autosomal recessive retinitis pigmentosa and Leber congenital amaurosis. Hum Mutat 2007, 28:511-516.

36. Pomares E, Riera M, Permanyer J, Méndez P, Castro-Navarro J, AndrésGutiérrez A, Marfany G, Gonzàlez-Duarte R: Comprehensive SNP-chip for retinitis pigmentosa-Leber congenital amaurosis diagnosis: new mutations and detection of mutational founder effects. Eur J Hum Genet 2010, 18:118-124

37. Aldahmesh MA, Safieh LA, Alkuraya H, Al-Rajhi A, Shamseldin H, Hashem M, Alzahrani F, Khan AO, Alqahtani F, Rahbeeni Z, Alowain M, Khalak H, Al-Hazzaa $\mathrm{S}$, Meyer BF, Fowzan S: Molecular characterization of retinitis pigmentosa in Saudi Arabia. Mol Vis 2009, 15:2464-2469.

38. ClinicalTrials.gov database [http://clinicaltrials.gov/]

39. LiT, Sandberg MA, Pawlyk BS, Rosner B, Hayes KC, Dryja TP, Berson EL: Effect of vitamin A supplementation on rhodopsin mutants threonine$17 \rightarrow$ methionine and proline-347 $\rightarrow$ serine in transgenic mice and in cell cultures. Proc Nat/ Acad SciU S A 1998, 95:11933-11938.

40. Berson EL, Rosner B, Sandberg MA, Hayes KC, Nicholson BW, Weigel-DiFranco C, Willett W: A randomized trial of vitamin $A$ and vitamin $E$ supplementation for retinitis pigmentosa. Arch Ophthalmol 1993, 111:761-772.

41. Mendes HF, Cheetham ME: Pharmacological manipulation of gain-offunction and dominant-negative mechanisms in rhodopsin retinitis pigmentosa. Hum Mol Genet 2008, 17:3043-3054.

42. Delyfer MN, Léveillard T, Mohand-Saï S, Hicks D, Picaud S, Sahel JA: Inherited retinal degenerations: therapeutic prospects. Biol Cell 2004, 96:261-269.

43. Wright AF, Chakarova CF, Abd El-Aziz MM, Bhattacharya SS: Photoreceptor degeneration: genetic and mechanistic dissection of a complex trait. Nat Rev Genet 2010, 11:273-284

44. Yang Y, Mohand-Said S, Danan A, Simonutti M, Fontaine V, Clerin E, Picaud S, Léveillard T, Sahel JA: Functional cone rescue by RdCVF protein in a dominant model of retinitis pigmentosa. Mol Ther 2009, 17:787-795.

45. MacDonald IM, Sauve Y, Sieving PA: Preventing blindness in retinal disease: ciliary neurotrophic factor intraocular implants. Can J Ophthalmol 2007, 42:399-402.

46. Tao W: Application of encapsulated cell technology for retinal degenerative diseases. Expert Opin Biol Ther 2006, 6:717-726.

47. Smith AJ, Bainbridge JW, Ali RR: Prospects for retinal gene replacement therapy. Trends Genet 2009, 25:156-165.

48. Bainbridge JW, Ali RR: Success in sight: the eyes have it! Ocular gene therapy trials for LCA look promising. Gene Ther 2008, 15:1191-1192.

49. Bainbridge JW, Smith AJ, Barker SS, Robbie S, Henderson R, Balaggan K, Viswanathan A, Holder GE, Stockman A, Tyler N, Petersen-Jones S, Bhattacharya SS, Thrasher AJ, Fitzke FW, Carter BJ, Rubin GS, Moore AT, Ali RR: Effect of gene therapy on visual function in Leber's congenital amaurosis. N Engl J Med 2008, 358:2231-2239.
50. Cideciyan AV, Aleman TS, Boye SL, Schwartz SB, Kaushal S, Roman AJ, Pang JJ, Sumaroka A, Windsor EA, Wilson JM, Flotte TR, Fishman GA, Heon E, Stone EM, Byrne BJ, Jacobson SG, Hauswirth WW: Human gene therapy for RPE65 isomerase deficiency activates the retinoid cycle of vision but with slow rod kinetics. Proc Natl Acad Sci U S A 2008, 105:15112-15117.

51. Maguire AM, Simonelli F, Pierce EA, Pugh EN Jr, Mingozzi F, Bennicelli J, Banfi S, Marshall KA, Testa F, Surace EM, Rossi S, Lyubarsky A, Arruda VR, Konkle B, Stone E, Sun J, Jacobs J, Dell'Osso L, Hertle R, Ma JX, Redmond TM, Zhu X, Hauck B, Zelenaia O, Shindler KS, Maguire MG, Wright JF, Volpe NJ, McDonnell $J W$, Auricchio A, High KA, Bennett J: Safety and efficacy of gene transfer for Leber's congenital amaurosis. N Engl J Med 2008, 358:2240-2248.

52. Georgiadis A, Tschernutter M, Bainbridge JW, Robbie SJ, McIntosh J, Nathwani AC, Smith AJ, Ali: RRAAV-mediated knockdown of peripherin-2 in vivo using miRNA-based hairpins. Gene Ther 2010, 17:486-493.

53. Mooney I, LaMotte JA: A review of the potential to restore vision with stem cells. Clin Exp Optom 2008, 91:78-84.

54. Wang S, Lu B, Girman S, Duan J, McFarland T, Zhang QS, Grompe M, Adamus $G$, Appukuttan B, Lund R: Non-invasive stem cell therapy in a rat model for retinal degeneration and vascular pathology. PLoS One 2010, 5:e9200.

55. EsREtNet: Spanish Retinal Dystrophies Research Network [http://www. esretnet.org]

56. Francois J, Verriest G: Etude biometrique de la retinopathie pigmentaire. Ann Oculist (Paris) 1962, 195:937-951.

57. van den Born LI, Bergen AA, Bleeker-Wagemakers EMA: Retrospective study of registered retinitis pigmentosa patients in The Netherlands. Ophthalmic Paediatr Genet 1992, 13:227-236.

58. Gerding H, Busse H: Distribution of the frequency of various Mendelian modes of inheritance in families with retinopathia pigmentosa. Results of an evaluation of the RP register of the Munster University Ophthalmology Clinic. Ophthalmologe 1994, 91:322-328.

59. Jay M: On the heredity of retinitis pigmentosa. Br J Ophthalmol 1982 66:405-416.

60. Bundey S, Crews SJ: A study of retinitis pigmentosa in the city of Birmingham. II Clinical and genetic heterogeneity. J Med Genet 1984, 21:421-428.

61. Berson EL, Rosner B, Simonoff E: Risk factors for genetic typing and detection in retinitis pigmentosa. Am J Ophthalmol 1980, 89:763-775.

62. Imaizumi K: Statistical investigation on retinitis pigmentosa. Jpn J Clin Ophthalmol 1971, 25:293-304

63. Hayakawa M, Fujiki K, Kanai A, Matsumura M, Honda Y, Sakaue H, Tamai M, Sakuma T, Tokoro T, Yura T, Kubota N, Kawano S, Matsui M, Yuzawa M, Oguchi Y, Akeo K, Adachi E, Kimura T, Miyake Y, Horiguchi M, Wakabayashi K, Ishizaka N, Koizumi K, Uyama M, Ohba N, et al: Multicenter genetic study of retinitis pigmentosa in Japan: I. Genetic heterogeneity in typical retinitis pigmentosa. Jpn J Ophthalmol 1997, 41:1-6.

64. Fei YJ: Genetic segregation analysis of retinitis pigmentosa. Zhonghua Yan Ke Za Zhi 1992, 28:67-70.

65. Oswald AH, Goldblatt J, Sampson G, Clokie R, Beighton P: Retinitis pigmentosa in South Africa. S Afr Med J 1985, 68:863-866.

66. Pearlman JT, Flood TP, Seiff SR: Retinitis pigmentosa without pigment. Am J Ophthalmol 1976, 81:417-419.

doi:10.1186/gm155

Cite this article as: Ayuso C, Millan JM: Retinitis pigmentosa and allied conditions today: a paradigm of translational research. Genome Medicine 2010, 2:34. 